University of Nebraska - Lincoln

DigitalCommons@University of Nebraska - Lincoln

2006

\title{
A Convective Line with Leading Stratiform Precipitation from BAMEX
}

\author{
Brandom Storm \\ University of Nebraska-Lincoln \& Texas Tech University, Lubbock, brandon.storm@ttu.edu \\ Matthew D. Parker \\ North Carolina State University, Raleigh \\ David P. Jorgensen \\ NOAA/NSSL/Warning R\&D Division, Norman
}

Follow this and additional works at: https://digitalcommons.unl.edu/natrespapers

Part of the Natural Resources and Conservation Commons, Natural Resources Management and Policy Commons, and the Other Environmental Sciences Commons

Storm, Brandom; Parker, Matthew D.; and Jorgensen, David P., "A Convective Line with Leading Stratiform Precipitation from BAMEX" (2006). Papers in Natural Resources. 1166.

https://digitalcommons.unl.edu/natrespapers/1166

This Article is brought to you for free and open access by the Natural Resources, School of at DigitalCommons@University of Nebraska - Lincoln. It has been accepted for inclusion in Papers in Natural Resources by an authorized administrator of DigitalCommons@University of Nebraska - Lincoln. 


\title{
A Convective Line with Leading Stratiform Precipitation from BAMEX
}

\author{
BRANDON A. STORM* \\ Department of Geosciences, University of Nebraska_Lincoln, Lincoln, Nebraska \\ MATTHEW D. PARKeR \\ Department of Marine, Earth, and Atmospheric Sciences, North Carolina State University, Raleigh, North Carolina \\ DAVID P. JORGENSEN \\ NOAA/NSSL/Warning R\&D Division, Norman, Oklahoma
}

(Manuscript received 2 February 2006, in final form 18 July 2006)

\begin{abstract}
On 31 May 2003, a front-fed convective line with leading stratiform precipitation (FFLS) was observed during the Bow Echo and Mesoscale Convective Vortex Experiment (BAMEX). The high-resolution BAMEX measurements provided one of the first opportunities to thoroughly observe the characteristics of an FFLS system. The 31 May system had an overturning updraft during its early stages, and produced leading stratiform precipitation. As the system matured, a jump updraft developed and the system began to produce trailing stratiform precipitation. It appears that this transition was facilitated by a local decrease in the low-level line-perpendicular vertical wind shear over time, as well as an increase in the surface cold pool's strength. The BAMEX data further help to address the question of how FFLS systems can be long lived when their inflow passes through the line-leading precipitation: preline soundings suggest a destabilization mechanism resulting from the vertical profile of cooling within the leading stratiform precipitation. This destabilization also helps to explain the 31 May convective system's persistence in an environment with very low CAPE.
\end{abstract}

\section{Introduction}

Mesoscale convective systems (MCSs) impact society by producing a large number of flash floods, along with many other types of severe weather, including high winds, large hail, and sometimes tornadoes (Fritsch and Forbes 2001). The total local rainfall accumulation, and hence the severity of flooding from an MCS can be largely related to its organizational mode and motion relative to a point (Doswell et al. 1996). To better understand the commonality of various MCS organiza-

\footnotetext{
* Current affiliation: Wind Science and Engineering Research Center, Department of Civil Engineering, Texas Tech University, Lubbock, Texas.

Corresponding author address: Brandon A. Storm, Wind Science and Engineering Research Center, Texas Tech University, Lubbock, TX 79409-1023.

E-mail: brandon.storm@ttu.edu
}

tional modes, Parker and Johnson (2000, hereafter PJ00) investigated the reflectivity patterns of 88 midlatitude linear convective systems. They classified the observed MCSs into three archetypes: those with convective lines and predominantly trailing stratiform precipitation (TS), leading stratiform precipitation (LS), or parallel stratiform precipitation (PS). They found that TS systems were most common, accounting for nearly $60 \%$ of their sample. However, roughly $20 \%$ of their cases were classified as LS systems, and another $20 \%$ were classified as PS systems. PJ00 unexpectedly found that, on average, LS MCSs had mean lowertropospheric inflow that passed through their preline precipitation. Such systems, hereafter referred to as "front-fed" LS (FFLS) systems, are the focus of the present study.

From 0100 to 0430 UTC 31 May 2003, an FFLS MCS traversed eastern Illinois and western Indiana, where it was sampled by multiple platforms as a part of the Bow Echo and Mesoscale Convective Vortex (MCV) Ex-

DOI: $10.1175 /$ MWR3392.1 
periment (BAMEX; Davis et al. 2004). Such systems appear to be relatively common (e.g., PJ00), and yet are poorly understood; indeed, the sampling strategy for 31 May 2003 was somewhat hindered because the organizational mode surprised BAMEX nowcasters. Parker and Johnson (2004a,b,c, hereafter PJ04a, PJ04b, and PJ04c, respectively) used idealized numerical simulations to study LS systems. However, few prior observational studies were available to verify these modeling experiments. The present case study of this archetypal FFLS system seeks to evaluate some of PJ04a,b,c's proposed hypotheses for the LS systems' structures and dynamics, and thereby to fill a gap in the knowledge base.

PJ04c developed a conceptual model for FFLS systems (Fig. 1) based upon cases documented by Grady and Verlinde (1997), Nachamkin et al. (2000), and PJ00. In this conception, the main feature of an FFLS system is its overturning updraft, which is composed of front-to-rear lower-tropospheric inflow that ascends and is accelerated forward, rendering rear-to-front flow in the middle and upper troposphere. This rear-to-front flow aloft is the predominant source of humidity and hydrometeors for the leading stratiform region (PJ04c).

PJ04a,b,c investigated the governing dynamics of FFLS systems, and found that both the lowertropospheric (0-3 km) and mid-upper-tropospheric (3$10 \mathrm{~km}$ ) vertical wind shear contributed to the flow structures in an FFLS system. The line-perpendicular shear in the lowest $3 \mathrm{~km}$ is associated with downsheardirected dynamic pressure gradient accelerations of updraft air. In turn these render deeper and more upright low-level updrafts, giving inflowing air parcels more time to experience the cold pool's upward forcing, and to accumulate downshear acceleration. In the presence of deep line-perpendicular shear, air also continues to be accelerated downshear farther aloft, additionally contributing to the system's overturning updraft.

PJ04b also found that FFLS systems modify their preline wind profiles in a way that may hasten their demise. A strong front-to-rear midtropospheric inflow jet may develop in response to a preline pressure minimum beneath the system's buoyant leading anvil. This jet entails decreased low-level vertical shear in the preline region (PJ04a,b), which may explain the evolution of many FFLS systems into TS systems.

PJ00 and others have also questioned how FFLS systems can be long lived despite inflow of evaporatively cooled preline air into the system. PJ04b found that inflowing air can actually be destabilized as it passes through the preline precipitation, leading to a stable and long-lived system. If the layer of air flowing into the system is relatively shallow, the evaporation of precipi-

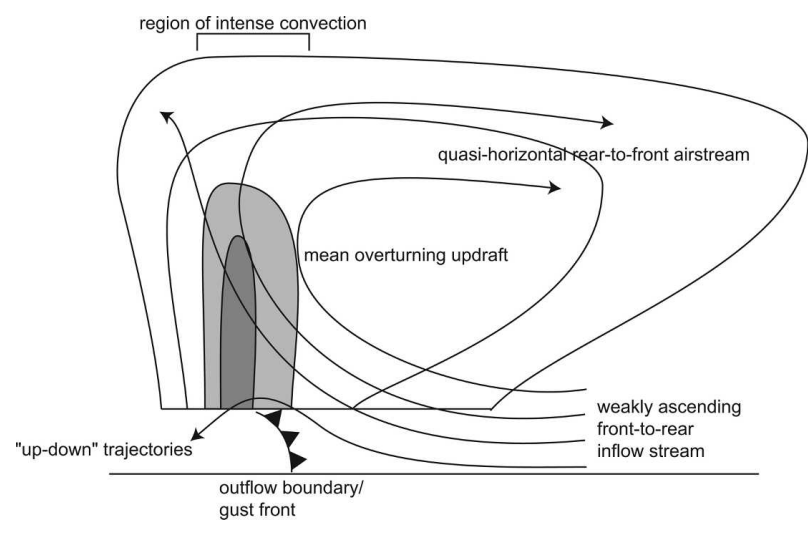

FIG. 1. Conceptual model of a front-fed convective line with leading precipitation, viewed in a vertical cross section oriented perpendicular to the convective line and parallel to its motion (PJ04c).

tation into that layer would cool it, adding convective inhibition (CIN) with respect to the original environment. However, PJ04b found that the cooling was vertically distributed throughout a fairly deep front-to-rear storm-relative inflow layer that was potentially unstable. Because the cooling increased with height up to the melting level, it actually destabilized the preline environment via a mechanism similar to that discussed by Mechem et al. (2002) and Knight et al. (2004).

The preceding hypotheses for FFLS systems have yet to be tested with observational data. Therefore, the present study aimed to develop a better understanding of the FFLS system's flow structures, dynamics, and evolution by assessing the realism of the numerical simulations, and by searching for unexpected features that were not produced in the simulations.

This paper describes various aspects of FFLS systems in turn. Section 2 provides information about data and methods used for this study. Section 3 provides an overview of the system under investigation. Section 4 discusses the dynamics and kinematics of the system at key times. Section 5 discusses the destabilization of the environment ahead of the convective line. The paper then concludes with a review and some ideas for future work.

\section{Data and methods}

\section{a. Airborne Doppler radar}

Two airborne Doppler radars were commissioned for BAMEX and sampled the 31 May FFLS system: the National Oceanic and Atmospheric Administration (NOAA) P-3 tail radar and the Naval Research Laboratory (NRL) P-3 equipped with the Electra Doppler radar; the flight tracks of these aircraft in the vicinity of 

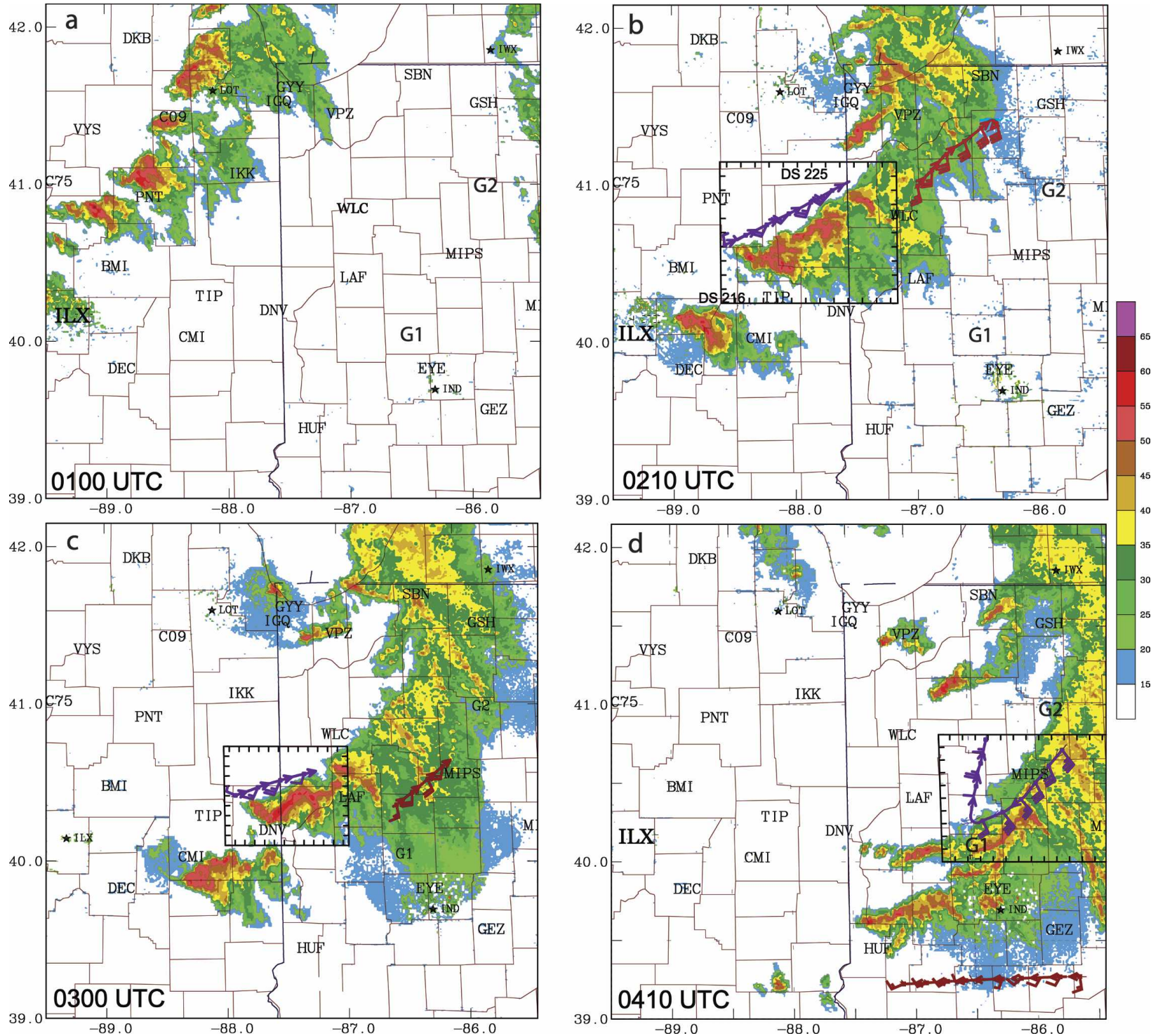

FIG. 2. Composite radar reflectivity (dBZ) from Weather Surveillance Radar-1988 Doppler radars and flight paths for 31 May 2003 BAMEX flight legs at (a) 0100, (b) 0210, (c) 0300, and (d) 0410 UTC. Flight tracks of NOAA P-3 (west of the convection) and NRL P-3 (east of the convection) are indicated by the purple and red line, respectively. The box indicates the area analyzed. For the line-perpendicular shear analysis, assumed line orientations were $45^{\circ}$ for $0210 \mathrm{UTC}, 50^{\circ}$ for $0300 \mathrm{UTC}$, and $45^{\circ}$ for $0410 \mathrm{UTC}$. In (b), DS tags indicate location of dropsondes (with BAMEX numbering). The reflectivity contour scale is shown to the right. Locations of ground-based soundings (G1, G2, and ILX), wind profiler (WLC), and surface stations are indicated..

the MCS are shown for various times in Fig. 2. This study relied mainly upon data from the NOAA P-3, which flew much closer to the system's convective line. The airborne Doppler radars use a strategy known as the fore/aft scanning technique (FAST; Jorgensen et al. 1996); on the NOAA P-3, the radar alternated between forward-canted and rearward-canted scans. Where two radar beams intersect, pseudo-dual-Doppler calculations can then be performed to retrieve the horizontal and vertical wind fields (following the methods of Jor- gensen et al. 1996). The FAST scanning method yields horizontal beams intersecting every $\sim 1.4 \mathrm{~km}$ for the NOAA P-3 radar (Jorgensen et al. 1983, 1996).

The data were corrected for aircraft motion and then advected to common times using measured storm motions to adjust for the time lag between samples by the two radar beams. After these corrections, the data were then interpolated to a Cartesian grid with a horizontal spacing of $1.5 \mathrm{~km}$ and a vertical spacing of $500 \mathrm{~m}$; the lowest analysis height was $1.5 \mathrm{~km}$ AGL. A two-step 
Leise filter was applied, after which vertical velocities were computed iteratively via downward integration, ${ }^{1}$ using the technique of O'Brien (1970) and enforcing $w=0$ at both the surface and echo top. The strengths and limitations of these airborne radar processing techniques were discussed by Jorgensen et al. (1996, 1997).

\section{b. Surface and upper-air observations}

Measurements from the National Weather Service (NWS) Automated Surface Observing System and Automated Weather Observations System, with observing frequencies from $1 \mathrm{~min}$ to $1 \mathrm{~h}$, were used to evaluate the convective system's environment; the locations of significant surface stations are shown by their three-letter identifiers in Fig. 2. Ground-based soundings were released from two locations in the system's path [shown by identifiers for the GPS/Loran Atmospheric Sounding System (GLASS) sounding site 1 (G1) and GLASS sounding site 2 (G2) in Fig. 2], at approximately hourly intervals. A Learjet also released dropsondes around the system; the locations of two dropsondes used to assess cold pool strength are denoted in Fig. 2b (DS 216 and DS 225). Conventional operational data were also used, including NOAA Profiler Network vertical wind profiles and operational NOAA/NWS soundings; the locations of two key sites, the Wolcott, Indiana (WLC), profiler and the Lincoln, Illinois (ILX), sounding site, are shown by their three-letter identifiers in Fig. 2.

\section{System overview}

\section{a. Large-scale environment}

At 0000 UTC 31 May 2003, around the time that the organized convection was developing and moving into Illinois, a deep midlatitude cyclone (Figs. 3a,b) was located over southern Wisconsin, with frontal boundaries extending to its south and southwest (Fig. 3a). This cyclone tracked southeastward into northern Illinois during the episode. Southerly winds in the warm sector and ahead of the warm front transported moist air into the region. Paired with steep regional lapse rates, this entailed instability, with surface-based CAPE (SBCAPE) around $2400 \mathrm{~J} \mathrm{~kg}^{-1}$ in the warm sector at Davenport, Iowa (DVN), and approximately $550 \mathrm{~J} \mathrm{~kg}^{-1}$ in the cold sector at ILX (Fig. 4) at 0000 UTC 31 May 2003. The upper-tropospheric disturbance was an open trough (e.g., at 500 hPa; Fig. 3c), positioned such that there was

\footnotetext{
${ }^{1}$ The reader should keep in mind that, even though the divergence is integrated from the echo top downward, there is still uncertainty in the computed magnitudes for $w$ because there were no radar data below $1.5 \mathrm{~km}$ AGL (where the divergence may be quite large)
}

cyclonic vorticity advection (CVA) aloft over the region. Finally, an upper-tropospheric jet streak (e.g., at 500 and 300 hPa; Figs. 3c,d) was present, entailing sufficient vertical wind shear for convective organization. Indeed, nearby wind profiles reveal that moderate to strong line-perpendicular (northwesterly) vertical wind shear prevailed throughout the region (Fig. 4; Table 1), a property of environments that support FFLS MCSs according to PJ04a,b,c. For future reference, upshear is defined to be northwest of the convective line, while downshear is defined to be southeast of the convective line.

In short, the synoptic pattern provided for a favorable thermodynamic and kinematic environment for the observed FFLS system. Increasing CVA with height, along with lower-tropospheric warm advection (Figs. 3a,b), would have entailed a background environment of ascent that was hospitable for the convective development. However, despite the large CAPE values in the warm sector (e.g., DVN), the FFLS system was moving southeastward into an environment (over eastern Illinois and Indiana) that had little to no CAPE (based on preline GLASS soundings: Table 1 and Fig. 4). The existence of deep convection within a region of minimal CAPE seems unusual. However, FFLS systems may be uniquely able to survive in such environments, a point that will be discussed in section 5 .

\section{b. System evolution}

Supercell thunderstorms formed in southern Wisconsin around 2130 UTC 30 May 2003 and developed southward into northern Illinois by 2330 UTC (not shown, although still somewhat evident in Fig. 2a). The supercellular mode was consistent with the significant deep-layer vertical wind shear, and several of these storms produced multiple tornadoes in Illinois. By 0100 UTC 31 May 2003, regions of leading stratiform precipitation had begun to develop downshear of the storms (Fig. 2a), and by 0200 UTC a convective line with FFLS characteristics existed on the southern end of the system, with weaker convection to its north (Fig. 2b). An additional, isolated supercell also developed to the southwest of the FFLS system (Fig. 2b), eventually joining with it. This general evolution is consistent with merging individual thunderstorm cold pools that produce widespread lifting along a linear gust front. Vertical motions at $1.5 \mathrm{~km}$ AGL derived from airborne radars are also consistent with the cold pools merging, as "slabular" lifting (James et al. 2005) was observed to increase along the convective line.

As the system continued to travel into Indiana, a line echo wave pattern (LEWP) developed around 0300 UTC on the southern end of the system [Fig. 2c; north- 

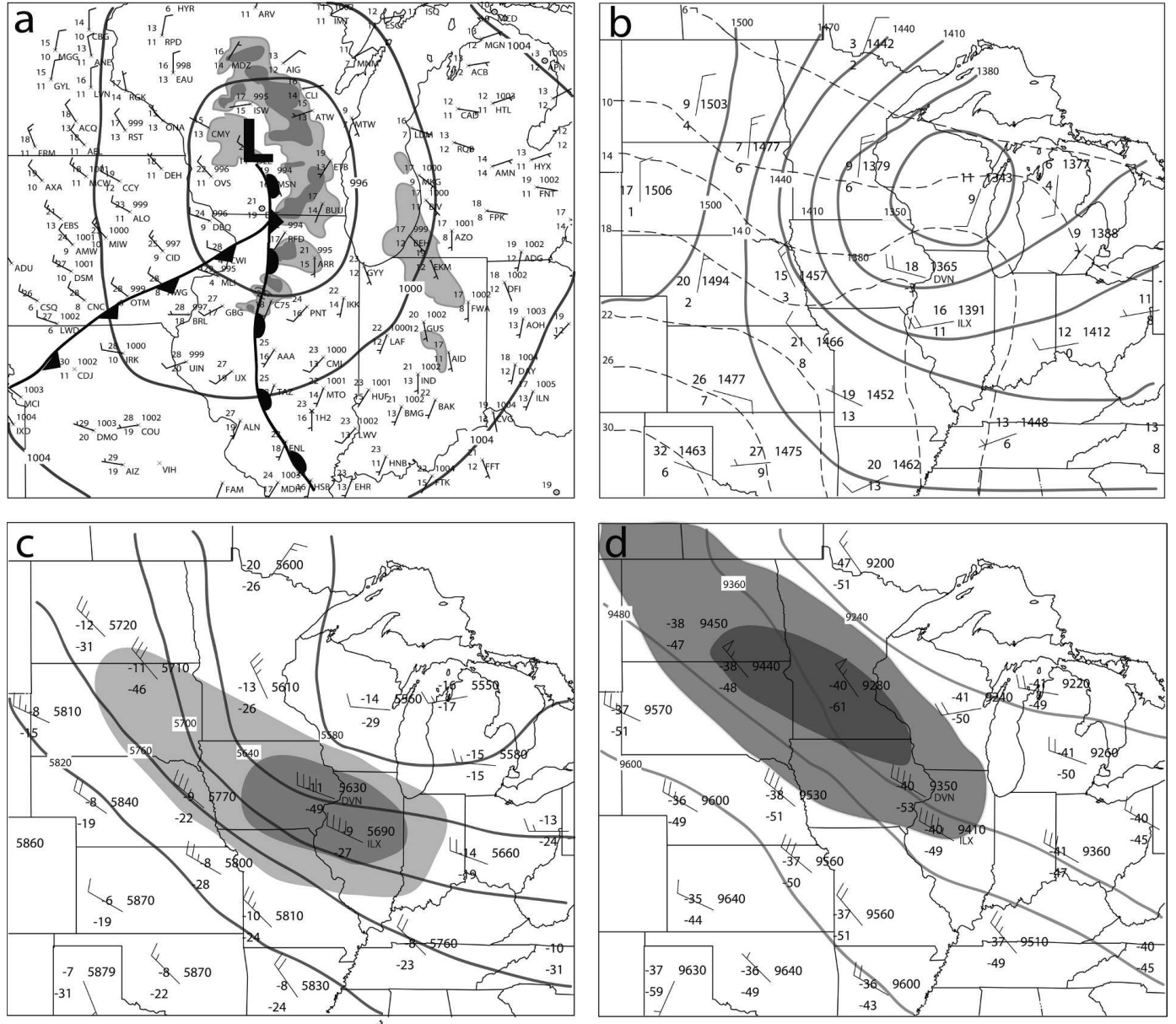

FIG. 3. The 0000 UTC 31 May 2003 analyses of conventional observations: (a) surface (MSL pressures contoured every $4 \mathrm{hPa}$, base reflectivity lightly shaded at $20 \mathrm{dBZ}$ and darkly shaded at $40 \mathrm{dBZ}$ ); (b) $850 \mathrm{hPa}$ (heights, solid contours every $30 \mathrm{~m}$; temperatures, dashed contours every $4^{\circ} \mathrm{C}$ ); (c) $500 \mathrm{hPa}$ (isotachs, shaded at 30 and $40 \mathrm{~m} \mathrm{~s}^{-1}$; heights, contoured every $60 \mathrm{~m}$ ); (d) $300 \mathrm{hPa}$ (isotachs, shaded at 40 and $50 \mathrm{~m} \mathrm{~s}^{-1}$; heights, contoured every $120 \mathrm{~m}$ ). (a)-(d) All show standard station models, with temperatures and dewpoint temperatures $\left({ }^{\circ} \mathrm{C}\right)$, heights $(\mathrm{m})$, and wind barbs (flag $=50 \mathrm{~s}^{-1}$, barb $=10 \mathrm{~m} \mathrm{~s}^{-1}$, and half barb $=5 \mathrm{~m} \mathrm{~s}^{-1}$ ).

northeast of Danville, IL (DNV), in Figs. 2 and 3]; associated with which was a mesocyclone that produced F0 surface damage (Wheatley et al. 2006). Soon thereafter, the system began to develop trailing stratiform precipitation aloft (interested readers can look ahead to Fig. 12) and became somewhat disorganized (Fig. 2d). The focus of the present study is upon the system's archetypal FFLS stages, during which the BAMEX airborne radar data were collected.

\section{Structure and dynamics of the FFLS system}

Representative data from the 31 May FFLS system's organizing, mature, and disorganizing stages are presented to depict its basic flow structures and evolution. The system was acquiring FFLS characteristics from roughly 0100 to 0230 UTC, was mature from roughly
0230 to $0330 \mathrm{UTC}$, and began to lose its organized FFLS structure thereafter (Fig. 2).

\section{a. Organizing stage}

For brevity, the system's early stages are represented by observations from the NOAA P-3 radar between 0159 and 0211 UTC (hereafter referred to as the 0210 UTC flight leg). The horizontal structure of the system at this time is shown in Fig. 5. Cross sections perpendicular to the convective line (Figs. 6a-c) correspond well to PJ04c's conceptual model (Fig. 1) for FFLS systems. In particular, during this flight leg the 31 May system evinced a predominant overturning updraft, as well as a weakly ascending front-to-rear inflow that passed through the line-leading precipitation, and an "up-down" flow branch, as shown by Knupp (1987), 


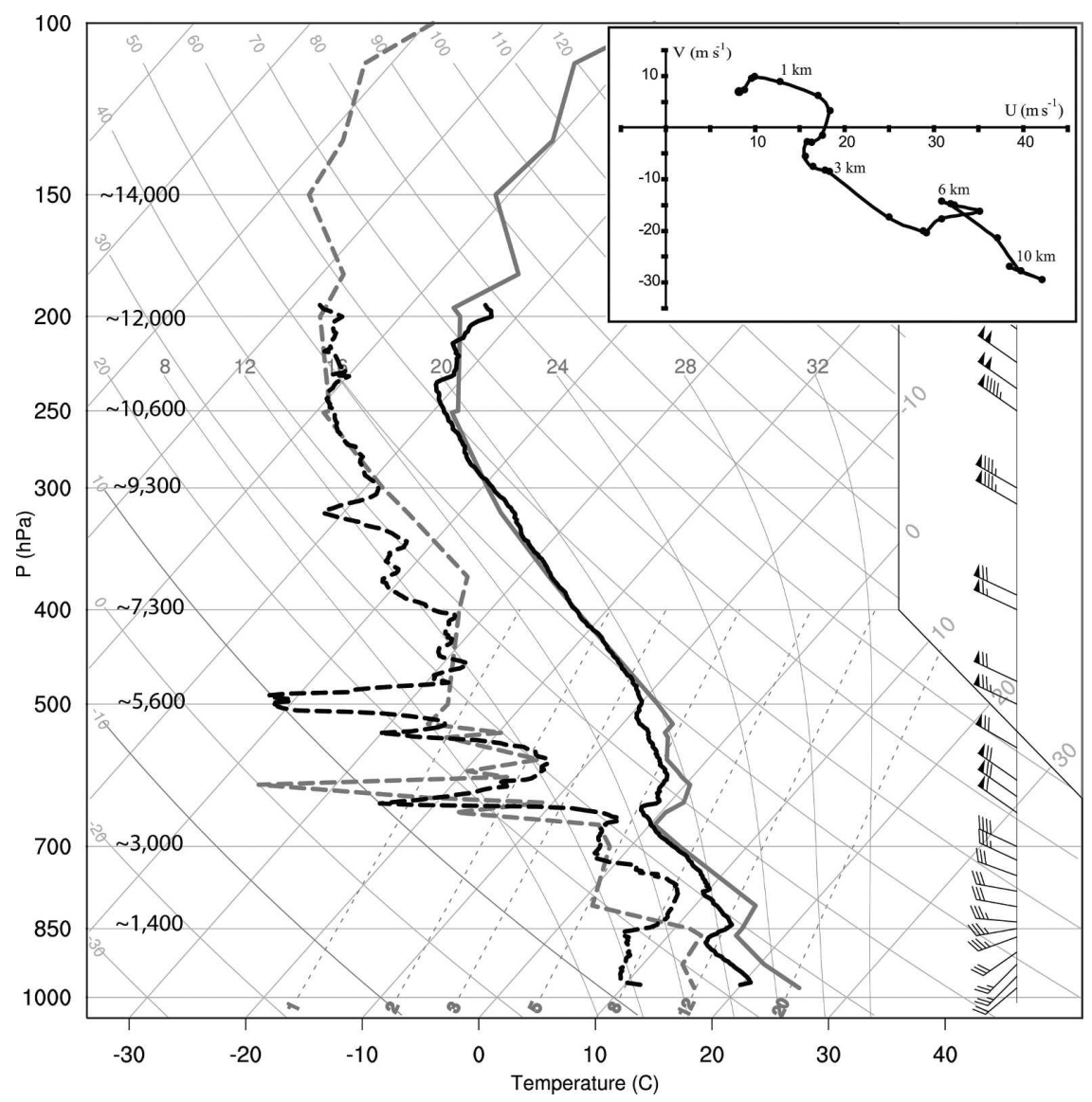

FIG. 4. Skew $T-\log p$ plot of rawinsonde temperature (solid line) and mixing ratio (dashed line) observations from ILX at 0000 UTC (lightly shaded) and from G1 at 0017 UTC (darkly shaded). The wind profile and hodograph are for the ILX sounding (flag $=25 \mathrm{~m} \mathrm{~s}^{-1}$, barb $=$ $5 \mathrm{~m} \mathrm{~s}^{-1}$, half barb $\left.=2.5 \mathrm{~m} \mathrm{~s}^{-1}\right)$. Approximate heights $(\mathrm{m} \mathrm{MSL})$ are shown for reference. The locations of G1 and ILX are shown in Fig. 2.

TABLE 1. Storm-relative line-perpendicular vertical wind shear parameters and thermodynamic indices from the WLC profiler at 0100 UTC, and G1 at 0017 UTC and G2 at 0125 UTC. Wind shears are expressed as shear vector magnitudes over specified layers. Line orientation of $45^{\circ}$ assumed for computation of line-perpendicular shear. Thermodynamic indices shown include SBCAPE, SBCIN, MUCAPE, and MUCIN. Locations of the data sources in Table 1 are shown in Fig. 2.

\begin{tabular}{clr}
\hline \hline \multicolumn{1}{c}{ Data source } & \multicolumn{1}{c}{ Parameter } & Obs value $\left(\mathrm{J} \mathrm{kg}^{-1} \mathrm{or} \mathrm{m} \mathrm{s}^{-1}\right)$ \\
\hline WLC (0100 UTC) (wind profiler) & 0-3-km line-perpendicular shear & 17 \\
& 0-6-km line-perpendicular shear & 31 \\
& 3-10-km line-perpendicular shear & 23 \\
\hline G1 (0017 UTC) & 0-3-km line-perpendicular shear & 31 \\
& 0-6-km line-perpendicular shear & 23 \\
& 3-10-km line-perpendicular shear & 0 \\
SBCAPE & 0 \\
SBCIN & 71 \\
MUCAPE & -10 \\
& MUCIN & 12 \\
& 0-3-km line-perpendicular shear & 24 \\
& 0-6-km line-perpendicular shear & 26 \\
3-10-km line-perpendicular shear & 0 \\
SBCAPE & 0 \\
SBCIN & MUCAPE & 0 \\
& MUCIN & 0
\end{tabular}




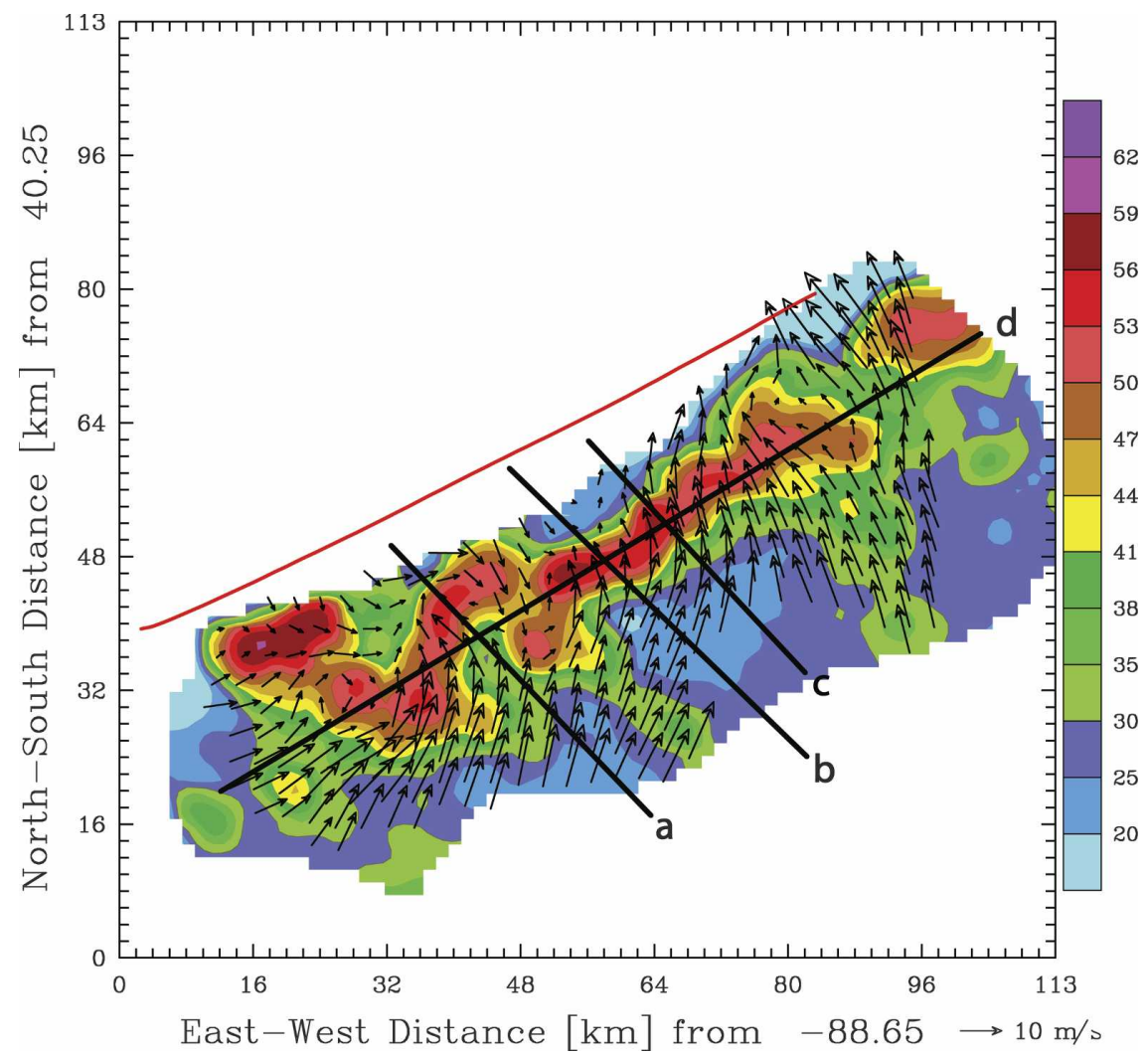

FIG. 5. Horizontal analysis of radar reflectivity and system-relative wind flow at $2.0 \mathrm{~km}$ AGL, valid at 0210 UTC 31 May 2003. The flight track of NOAA P-3 is shown in red. Black lines are locations of cross sections shown in Fig. 6. The reflectivity contour scale and the 10 $\mathrm{m} \mathrm{s}^{-1}$ scaling vector for winds are shown to the right and below, respectively.

feeding the surface outflow. Also, much as in the simulations of PJ04c, most of the updrafts were downshear of the heavy precipitation cores (i.e., to their right in Figs. 6a-c). The updrafts tilted rearward in the lower troposphere (owing to the large initial front-to-rear velocities of the inflowing parcels); as suggested by PJ04a,b,c, it appears that precipitation develops within the rearward-canted part of the updrafts (below $5 \mathrm{~km}$ AGL in Figs. 6a-c) and is largely unloaded before the updraft air acquires rear-to-fore momentum and overturns. The leading stratiform precipitation region then results from remaining, smaller hydrometeors that are advected forward.

Interestingly, the convective updrafts were fairly shallow (Fig. 6), extending only to 5-7 km AGL. This aspect may have resulted from the low environmental CAPE. Similar flow structures were also observed during the following flight leg (between 0213 and 0226 UTC, not shown). A cross section parallel to the convective line reveals minimal along-line wind (Figs. 5 and $6 \mathrm{~d}$ ); most of the flow was line perpendicular, such that the system was quasi $2 \mathrm{D}$.
The 31 May FFLS system also exhibited patches of enhanced reflectivity downshear from the convective region (e.g., around $x=25-30 \mathrm{~km}$ in Figs. 6a-c) some of which were associated with maximized $w$ (e.g., Fig. 6c). Such patches were also evident in the numerical simulations of PJ04a,b,c, who attributed them to pulses of enhanced hydrometeor content that were injected into the preline region by the periodic individual updrafts of the multicellular system. Unfortunately, the flight legs of the airborne radars were too long to temporally resolve the multicellular process in the 31 May MCS, but the enhanced reflectivity patches are consistent with the episodic forward advection of hydrometeors from the convective line. The relationship of the preline patches to upward motions in the midtroposphere also suggests that trapped gravity waves may have been present. We return briefly to this possibility later.

Because the FFLS system was not in steady state, and because the radar flight legs were too long to reasonably assess the temporal derivatives in the equations of motion, a rigorous analysis of radar-derived pressure 

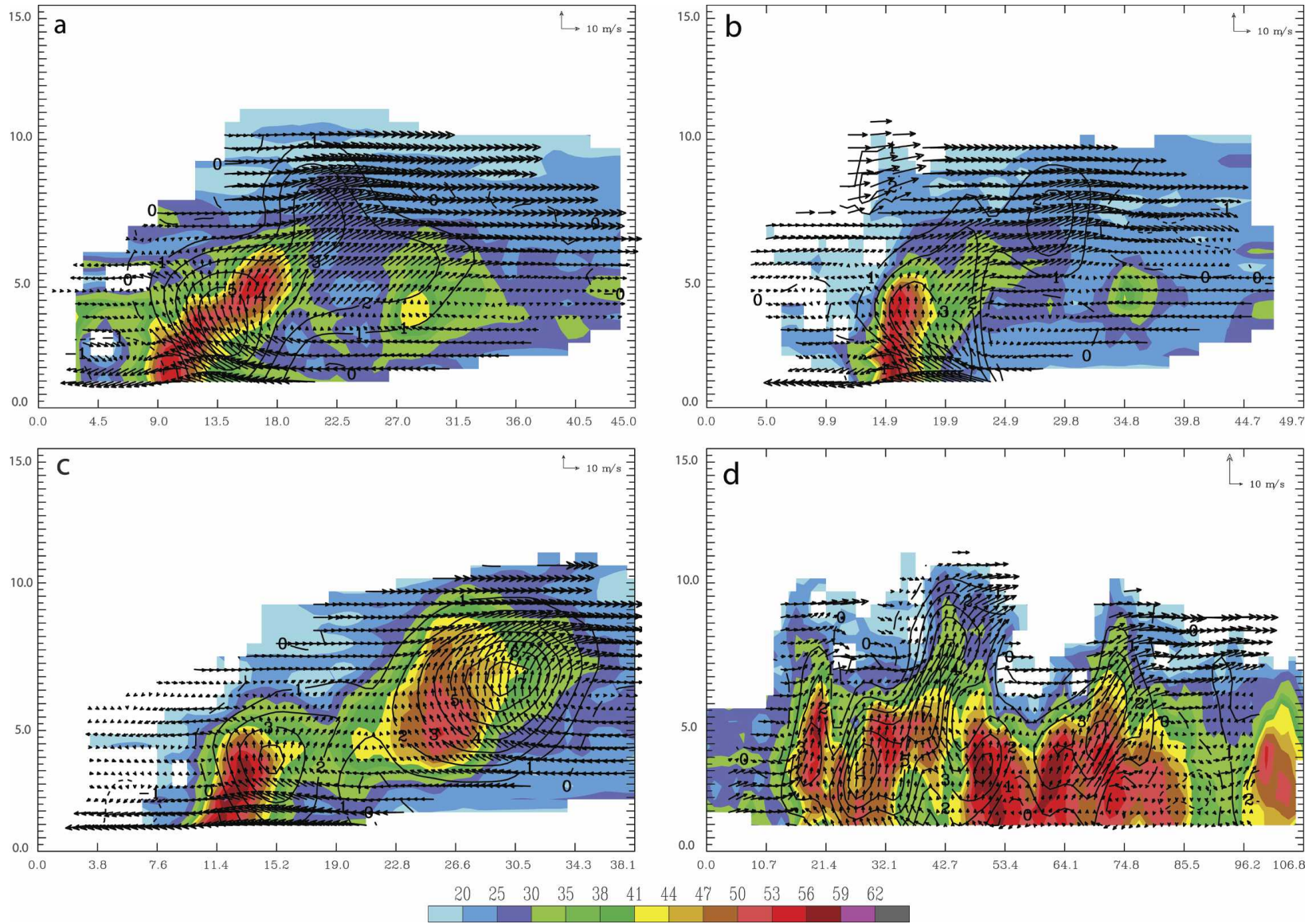

FIG. 6. Vertical cross sections of reflectivity and system-relative wind vectors at 0210 UTC 31 May 2003, along corresponding segments in Fig. 5. The reflectivity contour scale is shown below. The $10 \mathrm{~m} \mathrm{~s}^{-1}$ scaling vectors for winds are shown in the top right of each plot. The vertical axis represents heights AGL $(\mathrm{km})$ and the horizontal axis represents distance along the cross section $(\mathrm{km})$. The vertical velocity is contoured every $1 \mathrm{~m} \mathrm{~s}^{-1}$. Dashed contours represent negative vertical velocities.

perturbations (e.g., Gal-Chen 1978; Hane et al. 1981) was problematic. Nevertheless, the observed flow fields are consistent with the pressure perturbations discussed by PJ04a,b,c. The lower-tropospheric inflow arrived in the convective region with appreciable front-to-rear momentum (around $x=15 \mathrm{~km}, z=1-3 \mathrm{~km}$ in Figs. $6 \mathrm{a}-\mathrm{c})$. This inflow air then began to ascend and lose some of its rearward momentum; PJ04a,b,c attributed these behaviors to maximized lower-tropospheric pressure beneath the convective precipitation, associated hydrostatically with hydrometeor loading as well as the negative buoyancy of a surface cold pool. As the air continued to ascend in the updrafts, it acquired rearto-fore momentum and overturned $(x=12-16 \mathrm{~km}, z=$ 4-8 km in Figs. 6a-c), behavior consistent with maximized pressure on the upshear (left in Figs. 6a-c) sides of the updrafts and/or minimized pressure on the downshear (right in Figs. 6a-c) sides of the updrafts. PJ04a,b,c attributed comparable pressure maxima in their simulations to the dynamical effect of an updraft in shear, and to the buoyancy of the upper-tropospheric preline anvil. PJ04a,b,c also noted a cloud-top pressure maximum associated with the buoyancy of the the updraft region. The 31 May FFLS system's flow fields were also compatible with this, as the rear-to-fore flow in the preline anvil continued to intensify farther forward in the anvil region $(x=20-30 \mathrm{~km}, z=6-10 \mathrm{~km}$ in Figs. 6a-c).

Given the difficulties in assessing pressure gradient accelerations from the individual radar snapshots, it is notable that other authors (stemming from the original analysis of Rotunno et al. 1988) have cast this problem in terms of the balance between the environmental wind shear and the circulation generated baroclinically by a surface outflow. This vorticity-based approach is addressed in the next section.

\section{b. Mature stage}

The NOAA P-3 again sampled roughly the same region of the system from 0240 to 0300 UTC, as the FFLS 


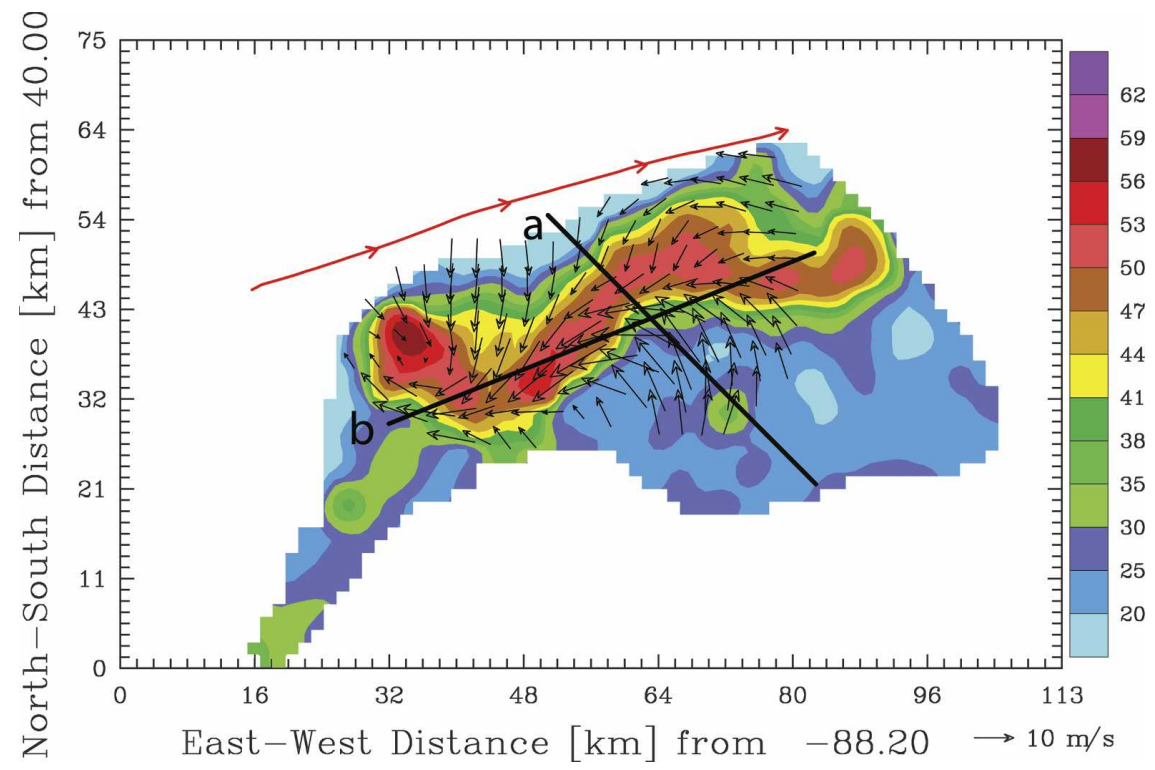

FIG. 7. Same as in Fig. 5, but valid at 0300 UTC. Black lines are locations of cross sections shown in Fig. 8.

system matured (Figs. 2b,c). Data from the 0300 UTC flight leg, including a pair of cross sections, serve to represent some of the complexities that emerged during this stage (Figs. 7 and 8). By this time, the low-level flow had acquired a significant line-parallel component within parts of the line's axis (Figs. 7 and 8b). A strong, anticyclonic line-end vortex (at $x=34 \mathrm{~km}, y=40 \mathrm{~km}$ in Fig. 7), as well as a patch of significant cyclonic vorticity $^{2}$ near the LEWP (at $x=48-60 \mathrm{~km}, y=30-40 \mathrm{~km}$ in Fig. 7), make it clear that the flow can no longer be treated as quasi 2D.

The updrafts at 0300 UTC continued to lean upshear, and an overturning updraft and the up-down inflow airstream were still present at this time (Fig. 8a). However, a front-to-rear-directed "jump" updraft (from 3 to $6 \mathrm{~km}$ AGL, extending to the west of $x=12$ in Fig. 8a), as well as rear inflow (from 2-3 km AGL at $x=0-9$ in Fig. 8a) with an overturning downdraft, were also evident (Fig. 8a). The presence of these latter features apparently marks the onset of the production of trailing precipitation; indeed, they are well-known hallmarks of the TS structure (Houze et al. 1989). Although no trailing precipitation was yet falling to the surface, an overhanging region of $>20-\mathrm{dBZ}$ reflectivity existed behind the line (left of $9.1 \mathrm{~km}$ in Fig. 8a), presumably because the jump updraft had begun to carry some of the hydrometers rearward. There was also evidence of a weak

\footnotetext{
${ }^{2}$ This became a well-defined mesocyclone by 0330 UTC. However, the airborne radars did not capture the whole feature, so a more detailed investigation was not possible.
}

jump updraft during 0210 UTC along some parts of the line (e.g., Fig. 6a); however, at 0300 UTC it was stronger, deeper, and more widespread along the line than at 0210 UTC. The LS-to-TS evolution in this case occurred gradually over time. The coexistence of these four fully articulated flow branches (overturning and jump updrafts, plus overturning and up-down downdrafts) is somewhat rare among convective systems (M. Moncrieff 2002, personal communication), but all four do appear together as the FFLS system evolves toward TS structure. The frequency of such complex flow fields in other nontraditional MCSs is unclear: more dualDoppler datasets would be of great interest.

PJ04a,b,c noted that the evolution from FFLS to TS systems is common in simulations, and that FFLS systems may decrease the preline vertical wind shear in a way that favors the transition. In the 31 May BAMEX case, a strong front-to-rear inflow jet had begun to develop by 0210 UTC and was strong and deep by 0300 UTC (centered around $3 \mathrm{~km}$ AGL from $14 \mathrm{~km} \leq x \leq$ $40 \mathrm{~km}$ in Fig. 8a). In their simulations, PJ04a,b found that such a jet developed in response to strongly minimized pressure on the downshear side of the convective line; PJ04a,b associated the pressure minimum with the updraft's curvature and the buoyancy of the uppertropospheric preline anvil. Because a strongly curved updraft and preline anvil were also observed in the 31 May system (e.g., Figs. 6a-c), its midlevel inflow jet likely had similar origins.

As a result of this stronger front-to-rear inflow jet, the preline 0-3-km line-perpendicular shear (expressed 

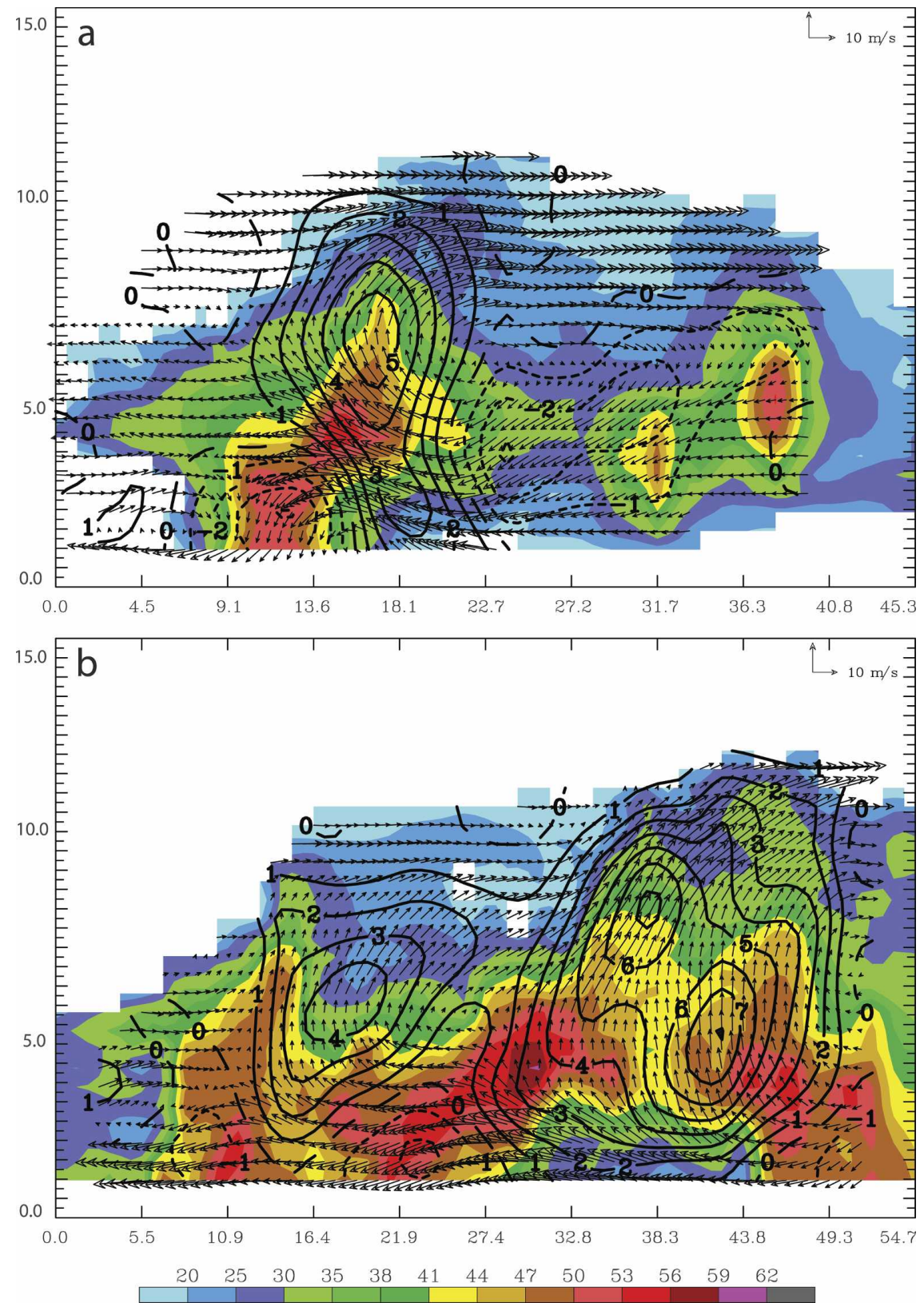

FIG. 8. Same as in Fig. 5, but valid at 0300 UTC, with cross sections along corresponding segments in Fig. 7.

as a shear vector magnitude) decreased from roughly $15-25 \mathrm{~m} \mathrm{~s}^{-1}$ at 0210 UTC to roughly $5-15 \mathrm{~m} \mathrm{~s}^{-1}$ at 0300 UTC (Figs. 9a,c); in tandem, the upper-level shear (3-8 $\mathrm{km}$ ) was observed to increase from 0210 to 0300 UTC (Figs. 9b,d).

PJ04b considered the impact of decreased lowertropospheric shear on the pressure gradient accelerations in an FFLS system. Because of the limitations of the radar-derived pressure retrievals in the present case, it is instead worthwhile to consider the more ho- listic perspective of Rotunno et al. (1988), that is, that the tilt of a convective updraft is influenced by the comparative strengths of the surface cold pool $C$ and the lower-tropospheric line-perpendicular vertical wind shear $\Delta U$. Following Rotunno et al. (1988), if the horizontal vorticity associated with the environmental wind shear is less than the horizontal vorticity baroclinically generated by the cold pool $(C>\Delta U)$, then the net circulation will tilt the updraft upshear. This would likely correspond to a front-fed line with trailing pre- 

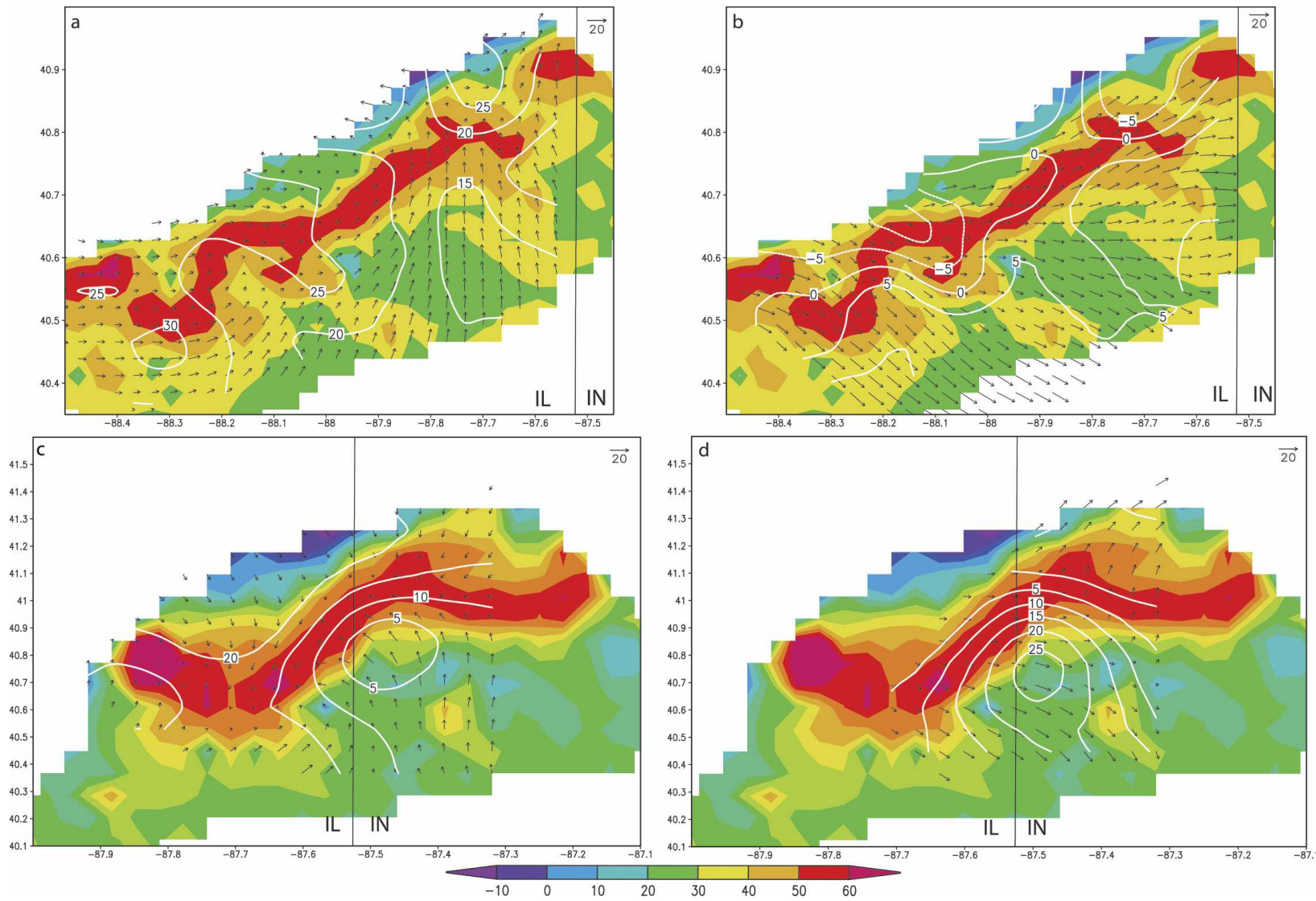

FIG. 9. Horizontal analysis of reflectivity (shaded) at $2 \mathrm{~km}$ for 31 May 2003: (a) 0210 UTC wind vectors at 3- and 0-3-km vector wind difference contoured every $5 \mathrm{~m} \mathrm{~s}^{-1}$, (b) 0210 UTC wind vectors at 8- and 3-8-km vector wind difference contoured every $5 \mathrm{~m} \mathrm{~s}^{-1}$, (c) 0300 UTC wind vectors at 3- and 0-3-km vector wind difference contoured every $5 \mathrm{~m} \mathrm{~s}^{-1}$, (d) 0300 UTC wind vectors at 8- and 3-8-km vector wind difference contoured every $5 \mathrm{~m} \mathrm{~s}^{-1}$. The reflectivity contour scale is shown at the bottom. The $20 \mathrm{~m} \mathrm{~s}^{-1} \mathrm{scaling}$ vector for winds is in the upper right.

cipitation. However, if the circulation generated by the cold pool is insufficient to offset that associated with the shear $(C<\Delta U)$, the updraft will tilt downshear. This would likely correspond to a front-fed line with leading precipitation.

The data did not permit rigorous computation of $C$. In fact, even the computation of $\Delta U$ is problematic, because some depth must be chosen over which to evaluate it. However, although a numerical assessment of the ratio $C / \Delta U$ would be inexact, the data do permit a reasonable assessment of the trends in $C$ and $\Delta U$. An increase in $C$ and decrease in $\Delta U$ over time would be qualitatively consistent with the observed LS-to-TS transition. As discussed above, the trend was for the lower-tropospheric line-perpendicular shear $\Delta U$ to decrease. To determine whether the cold pool strengthened over time, the postline surface pressure changes $\Delta P$ were used. Although the surface pressure change after the convective line's passage is not necessarily a full representation of $C$, hydrostatic balance implies that the pressure jump will be greater when the outflow is colder and deeper. We checked and supplemented the surface stations' measured $\Delta P$ with BAMEX upperair soundings, which provided exact measures of $C$ and which we then converted to surface pressure changes (following Bryan et al. 2004 and G. Bryan 2005, personal communication), for continuity with the surface data (see Fig. 10).

The observed surface pressure jump increased from 0100 to 0300 UTC in the vicinity of the primary FFLS system (Fig. 10), implying that the cold pool strengthened over time. ${ }^{3}$ The FFLS system's central convective line (the heavy line weight in Fig. 10) generally had the greatest $\Delta \mathrm{P}$, consistent with the location of heaviest precipitation. Unfortunately, no surface observations were available around 0200 UTC as the main FFLS line

\footnotetext{
${ }^{3}$ The decrease in $\Delta P$ between 0300 and 0400 UTC, appears to correspond to the increasing disorganization of the system after 0300 UTC.
} 


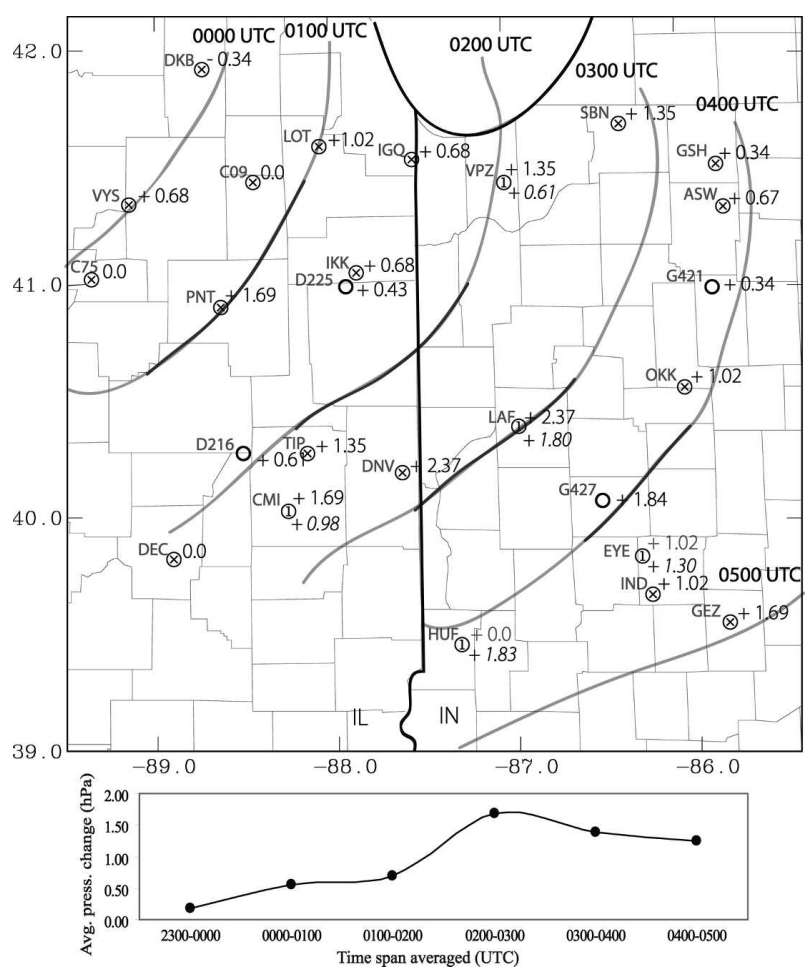

FIG. 10. Depiction of pressure changes upon the convective line's passage. (top) Isochrones are drawn for approximate location of the leading edge of the convective line every hour. The dark shading of the isochrones represents the area of the FFLS system investigated in this paper. Station identification letters appear to the upper left of the station location markers. Station location markers: data where 1-min surface observations were available (circled 1); data computed from either dropsondes or GLASS soundings (empty circles); and data where only 20-min (or less frequent) surface observations were available (circles with times signs). Pressure changes found using the 1-min data appear to the bottom right of the marker, while the changes computed from the coarser observations appear to the upper right. For stations Terre Haute, IN (HUF), and Indianapolis, IN (EYE), 20min data were unavailable, so hourly data were used. (bottom) Along-line-averaged pressure change $(\mathrm{hPa})$ over the given time interval. Averages were computed from the 20-min observations that were within $50 \mathrm{~km}$ of the main convective line (i.e., the dark segments in the top panel). The 50-km criterion excluded Decatur, IL (DEC); Goshen, IN (GSH); Warsaw, IN (ASW); South Bend, IN (SBN), and HUF from the averages.

crossed the Illinois and Indiana border. But, the general result of the cold pool strength increasing over time is not unexpected, as the earlier, more upright convective cells would produce heavier precipitation, leading to a significant amount of evaporative chilling. Weisman (1992) originally conceived of squall-line evolution in this way, and the FFLS simulations of PJ04a,b,c exhibit this behavior.

So, although exact computation of $C / \Delta U$ was not possible, it appears that the cold pool strength increased over time due to evaporative chilling, while $\Delta U$ de- creased over time due to the FFLS system's propensity to generate a midlevel front-to-rear inflow jet. Given the observed updraft structures, it is likely that the lowlevel shear was initially able to overwhelm the cold pool's circulation. The initially weak cold pool may be attributable to the low observed CAPE. Convection in such an environment would be weaker, and would produce a smaller quantity of hydrometeors that could be evaporated in the subcloud air. Indeed, the system under investigation was observed to have shallow updrafts with relatively small vertical velocities. However, over time the cumulative effect of many cells apparently led the cold pool to intensify and overwhelm the low-level shear. As the cold pool strengthened, the low-level shear was also decreasing. Therefore, the horizontal vorticity generated by the cold pool was able to produce updrafts that were more upright, and that eventually tilted upshear, which in turn led the system to evolve toward the TS structure.

Many of PJ04a,b,c's simulations produced this kind of LS-to-TS evolution, leading them to conclude that FFLS systems "provide a means for their own demise owing to their tendency to decrease the lower tropospheric wind shear." As noted earlier, in the 31 May case the upper-tropospheric shear increased in time, a feature that PJ04a,b,c and Coniglio et al. (2006) have shown to favor more intense, upright updrafts. However, by 0410 UTC 31 May (Fig. 12), because the inflowing air parcels retained most of their front-to-rear momentum in the lower troposphere, air in the weaker and shallower jump updrafts moved mainly rearward. The increased vertical shear aloft made little difference because much of the inflowing air exited the updraft before making it that far aloft.

\section{c. Disorganizing stage}

The NOAA P-3 again sampled roughly the same region of the system from 0400 to 0420 UTC, as the FFLS system became disorganized (Figs. 2c,d and 11). During this time, the flow throughout the depth of the updrafts was observed to be front to rear, and the system no longer exhibited any of the archetypal FFLS flow characteristics (Fig. 12). The region of TS precipitation continued to develop as a result of the increasingly dominant jump updraft carrying hydrometeors rearward.

\section{Destabilization}

As discussed in section 1, previous authors have wondered how FFLS systems could be long lived despite the inflow of evaporatively cooled preline air into the convective line. This is especially interesting in the case 


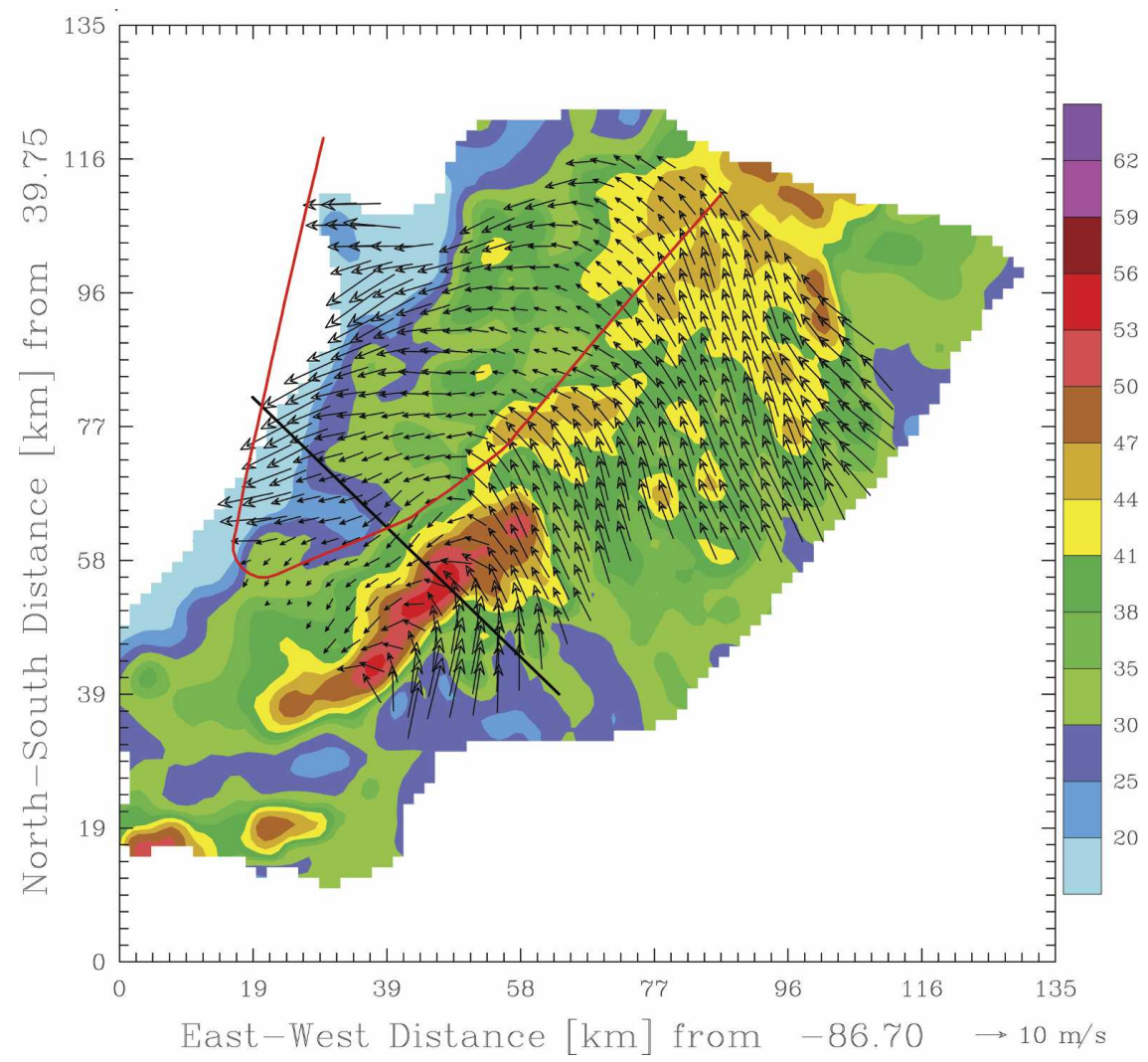

FIG. 11. Same as in Fig. 5, but valid at 0410 UTC. Black line is the location of cross section shown in Fig. 12.

of the 31 May FFLS system because it was able to survive in an environment with very little CAPE. PJ04b concluded that FFLS systems destabilize their inflow both through lifting and through a profile of diabatic cooling that increases with height. This chilling increased up to the melting level $(\sim 3 \mathrm{~km}$ AGL in their case). Similar destabilization of air beneath precipitating anvils has also been discussed by Mechem et al. (2002) and Knight et al. (2004). Multiple preline upperair observations from BAMEX were available on 31 May to address this hypothesis.

The sounding from G1 at 0017 UTC (light curves in Fig. 13), representative of the presystem environment, had around $50 \mathrm{~J} \mathrm{~kg}^{-1}$ of most unstable parcel CAPE (MUCAPE) and about $-10 \mathrm{~J} \mathrm{~kg}^{-1}$ of most unstable parcel CIN (MUCIN), using the parcel from $772 \mathrm{hPa}$. The sounding from G1 at 0329 UTC, released ahead of the convective line and near the stratiform precipitation region (dark curves in Fig. 13), had an MUCAPE of around $940 \mathrm{~J} \mathrm{~kg}^{-1}$ and $0 \mathrm{~J} \mathrm{~kg}^{-1}$ of MUCIN, using the parcel from $829 \mathrm{hPa}$. Though only $15 \mathrm{~J} \mathrm{~kg}^{-1}$ of SBCAPE was present in the G1 sounding at 0329 UTC, using the temperature and dewpoint from nearby surface stations would result in an approximate value of
$150 \mathrm{~J} \mathrm{~kg}^{-1}$. Clearly, the lower-middle troposphere was destabilized as the FFLS system approached; the lapse rate above $800 \mathrm{hPa}$ was steepened, and the temperature inversion around $600 \mathrm{hPa}$ was removed.

A comparison of the two soundings (Fig. 13) shows that the troposphere was cooler at 0329 UTC than at 0017 UTC throughout most of the layer below $400 \mathrm{hPa}$ (approx $7.3 \mathrm{~km}$ AGL). The latter sounding also was generally moistened (except between roughly 800 and $750 \mathrm{hPa}$ ). These are likely symptoms of evaporation and sublimation of the preline hydrometeors, and they also bear resemblance to Fovell's (2002) cool and moist tongue, which was associated with preline ascent in squall lines; because lower-tropospheric chilling produces a wave of ascent in the preline region, the two effects are somewhat convolved.

From $4 \mathrm{~km}$ AGL upward to the tropopause, the equivalent potential temperature $\theta_{e}$ had increased by as much as 5 K (Fig. 14); this increase, paired with the fact that the layer was nearly saturated and close to the pseudoadiabatic lapse rate (Fig. 13), supports the idea that higher $\theta_{e}$ air from the lower troposphere ascended within the convective updrafts, and then traveled forward into the preline anvil. Below $2 \mathrm{~km} \mathrm{AGL,} \theta_{e}$ also 


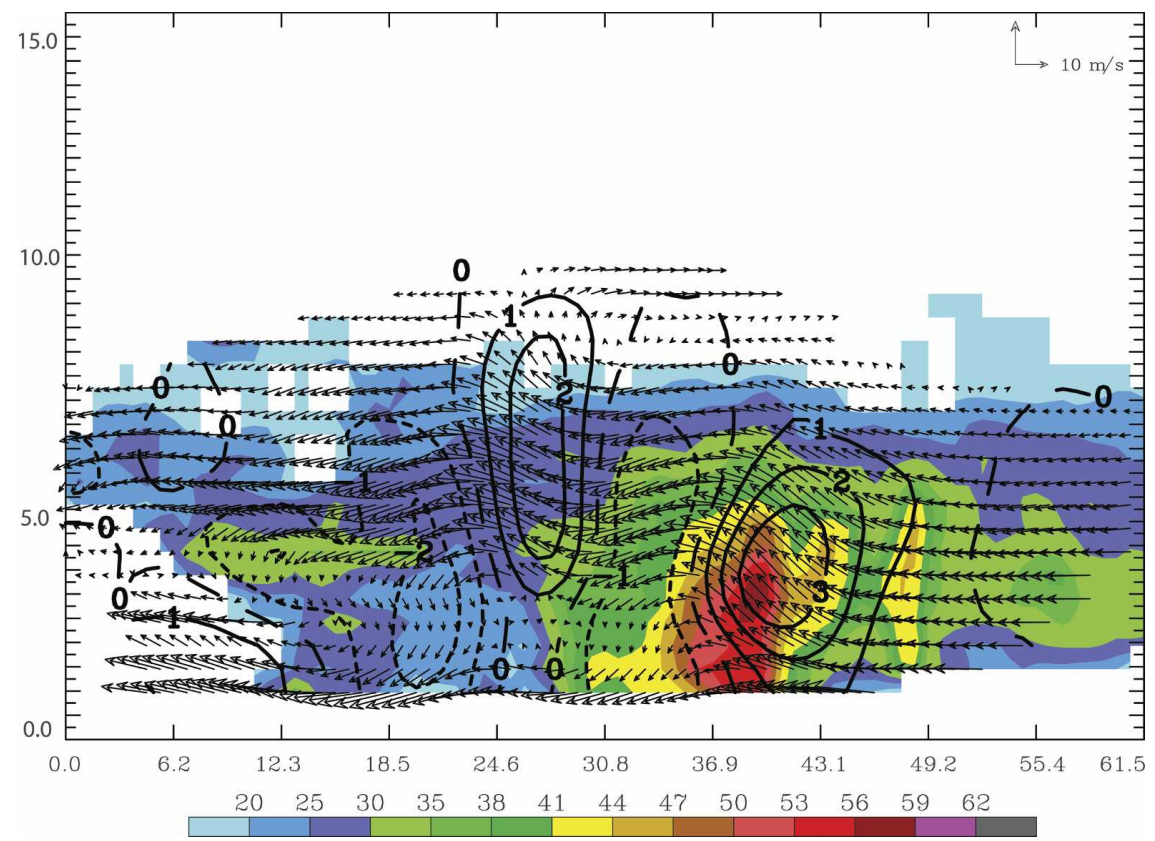

FIG. 12. Same as in Fig. 6, but valid at 0410 UTC, with the cross section along the segment in Fig. 11.

increased (Fig. 14). A survey of the regional lowertropospheric measurements (Figs. 3a,b) suggests that this was largely due to advection of moister air from the south (at the surface) and southwest (at $850 \mathrm{hPa}$ ); given the initial profile of $\theta_{e}$ and the 0329 UTC sounding's location in the preline precipitation, neither vertical rearrangement of mass nor diabatic heating can likely account for the observed spike in $\theta_{e}$ around $1.5 \mathrm{~km}$ AGL at 0329 UTC.

The subsaturated area between 800 and $650 \mathrm{hPa}$ (and

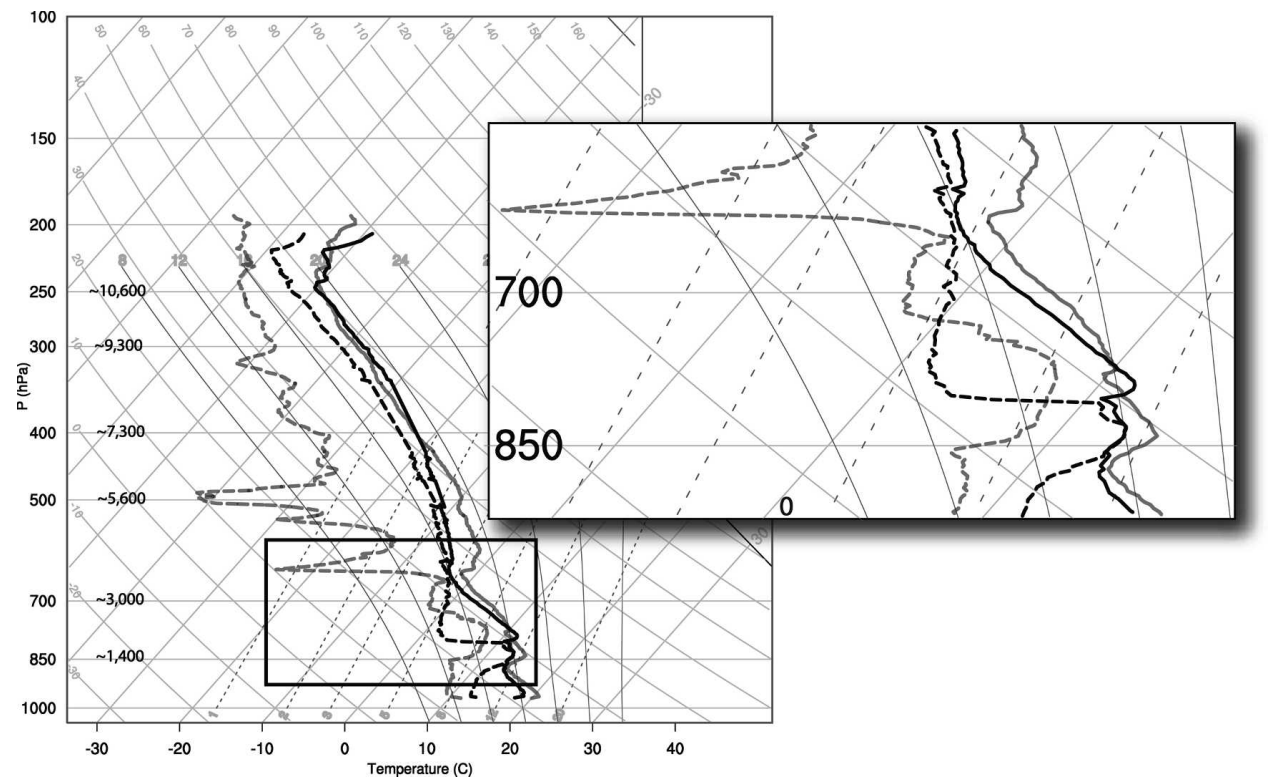

FIG. 13. Skew $T-\log p$ plot of rawinsonde temperature (solid line) and mixing ratio (dashed line) observations from G1 at 0017 UTC (lightly shaded) and 0329 UTC (darkly shaded) 31 May 2003 (location of G1 shown in Fig. 2). Approximate heights (m MSL) are shown for reference. The primary destabilized layers discussed in the text are magnified at right for clarity. 


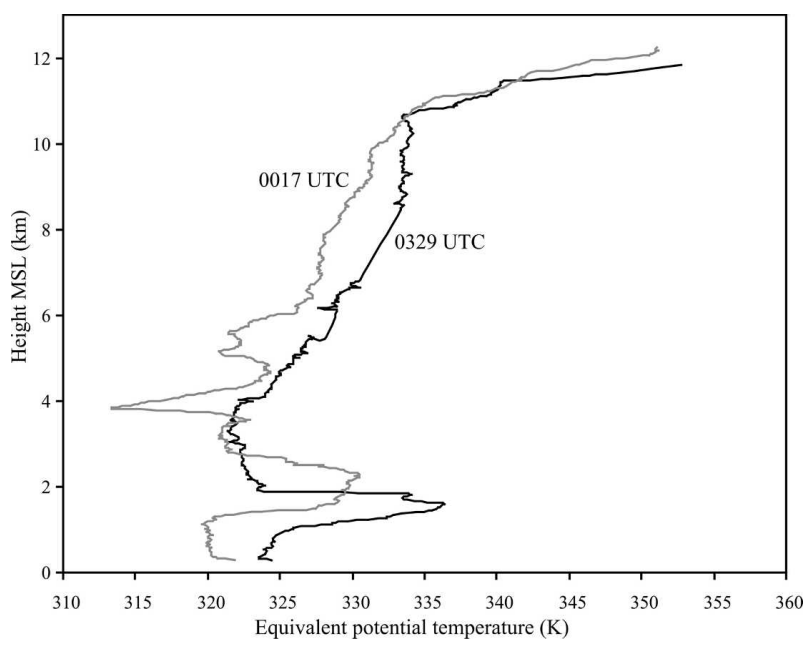

FIG. 14. The $\theta_{e}(\mathrm{~K})$ profile from G1 at 0017 UTC (lightly shaded) and 0329 UTC (darkly shaded) on 31 May 2003 (location of G1 shown in Fig. 2).

apparent drying between 800 and $750 \mathrm{hPa}$ ) may have been associated with a downdraft (active or recent). This is supported by the nearly constant value for $\theta_{e}$ in the 2-4-km layer (Fig. 14). The initial environment (0017 UTC in Fig. 13) had steep lapse rates below the temperature inversion near $600 \mathrm{hPa}$, suggesting that deep, penetrative, unsaturated downdrafts would be possible, especially given initial forcing from hydrometeor loading and phase changes. Notably, widespread subsidence was observed in the preline region of several radar cross sections (e.g., Fig. 8a).

Although the possible downdraft complicates the analysis, the destabilization mechanism proposed by PJ04b is still worth examining. The sounding at 0329 UTC suggests a cloud base around $650 \mathrm{hPa}$ (Fig. 14); this is approximately $3 \mathrm{~km} \mathrm{AGL}$, or $\leq 1 \mathrm{~km}$ above the bottom of the preline 30-dBZ radar echoes (e.g., Figs. 6 and 8). Below cloud base, and around the melting level, the net chilling increased with height, similar to what occurred in the simulations of PJ04b. Significant chilling and moistening were also observed from approximately 650 to $425 \mathrm{hPa}$, likely as a result of sublimation: the base state was quite dry above $600 \mathrm{hPa}$ (0017 UTC sounding in Fig. 13), and the preline precipitation region likely comprised predominantly snow and ice particles aloft, because most of the larger particles (e.g., rain and graupel) would fall out near the convective line.

PJ04b identified melting as a key contributor to preline destabilization in an FFLS simulation (using a basic ice microphysics parameterization). However, other observational studies (e.g., Leary and Houze 1979) have often revealed the presence of isothermal layers where significant melting of precipitation is occurring; the lack of such a layer in the 0329 UTC sounding argues that other diabatic processes may have predominated over melting in the present case. However, again it is possible that such an isothermal layer was locally obscured by the presence of an unsaturated downdraft.

PJ04b also cited lifting as a mechanism for destabilization in the preline region, and in this regard the "cool moist tongue" mechanism of Fovell (2002) may have been at work. However, this process alone would not entail the dramatic changes to $\theta_{e}$ such as were observed. Given the complexity of the flows and microphysics in the preline region, it is likely that multiple processes were playing a role. The combination of low-level moistening, steepened lapse rates below cloud base, and cooling above, resulted in a dramatically destabilized sounding from 800 to $425 \mathrm{hPa}$ in this case. The hypothesized effects of preline precipitation seem especially important to the longevity of FFLS systems in environments with minimal CAPE, as on 31 May 2003.

Some reviewers wondered about the scale over which this destabilization must occur in order for the FFLS system to survive, because the proposed mechanisms would only be active within the preline precipitation zone. The air parcels participating in the deep convective cells are subject only to the local vertical force balance, not to their buoyancy with respect to the external environment (e.g., Doswell and Markowski 2004). Therefore, although we cannot definitely quantify the horizontal scale of the destabilization with the current observations, it should be sufficient for the sounding to be destabilized in the immediate vicinity of the lifting (i.e., the outflow boundary). This is feasible because the inflow air must pass through the entire preline precipitation region on its way to the convective region.

\section{Conclusions}

\section{a. Summary}

This work utilized data from BAMEX to investigate an FFLS system. Airborne radar data provided one of the first detailed looks at an observed FFLS system. Primary findings include the following:

- During the early-to-mature stages the flow corresponded to the conceptual model proposed by PJ04c, with a predominant overturning updraft. During this time, the system almost exclusively produced lineleading precipitation.

- The system developed a strong front-to-rear midlevel inflow jet within the leading stratiform region. This 


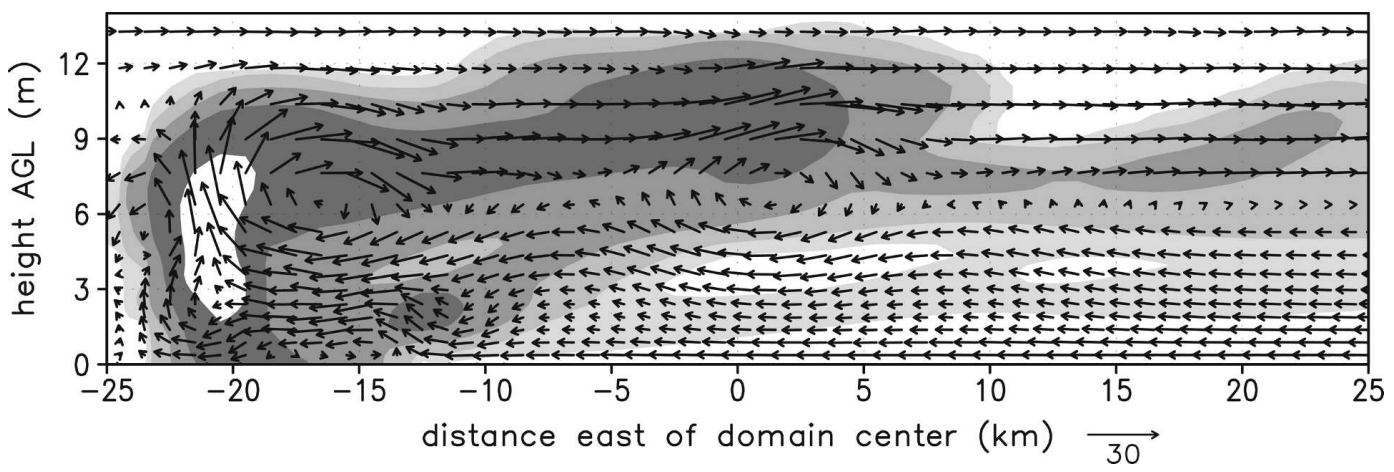

FIG. 15. Total hydrometeor mixing ratio (levels of shading are $0.02,0.08,0.32,1.28$, and $5.12 \mathrm{~g} \mathrm{~kg}^{-1}$ ) and wind vectors ( $\mathrm{m} \mathrm{s}^{-1}$, scaled as shown) at $t=2 \mathrm{~h}$ from the $2 \mathrm{D}$ control FFLS simulation of PJ04a.

jet entailed decreased lower-tropospheric lineperpendicular wind shear. The system's outflow also appeared to intensify during this period.

- In time, because of the decreased low-level shear and increased cold pool strength, the system evolved toward having a predominant jump updraft and producing trailing precipitation.

- Pre-MCS soundings suggest that the inflowing air was destabilized as it passed through the line-leading precipitation. MUCAPE increased thanks to moistening as well as cooling that increased with height. These effects seem to be consistent with sublimation, melting, and evaporation of the preline precipitation, as well as preline ascent.

This study is one of the first detailed observational studies of an FFLS system. The emerging conceptual model for FFLS systems should be further refined through additional work on this recurring yet inadequately studied convective mode.

\section{b. Future avenues}

This was a case study of one system, observed over limited time and space. Data with higher temporal resolution-and at least comparable spatial resolution and coverage-are needed to fully address nascent hypotheses for such nontraditional systems. Unfortunately, it seems somewhat unlikely that data of this quality will be collected in the near future; field campaigns focusing on these types of systems are not frequent. One avenue that may hold promise is that of dynamical data assimilation, in which observations constrain a dynamically consistent model simulation, providing a very high resolution dataset with extensive coverage. Recent studies have shown this approach to be quite faithful to reality, while providing far greater data coverage and adding more useful meteorological variables (Zhang et al. 2004).

The present system had distinct 3D features during its later stages, so it appears that any further numerical studies should use fully 3D configurations. There are several logical areas for future numerical experiments. For example, FFLS systems appear to develop in high shear environments that are also supportive of supercells. ${ }^{4}$ A supercell was observed just south of the 31 May system, and the main FFLS line also developed a mesocyclone. A better understanding of convective modes' sensitivities within high shear environments would be of definite interest.

The 31 May FFLS MCS exhibits regions of ascent and enhanced reflectivity within its preline precipitation region (Figs. 6a-c and 8a). Such features also appeared in the FFLS simulations of PJ04a,b,c (Fig. 15), however they were reluctant to further investigate these features for fear they were an artifact of the quasi-2D model framework. Even so, cutoff updraft features have been seen to take the form of gravity waves (buoyancy rolls) in the trailing anvils of TS systems (e.g., Yang and Houze 1995; Fovell and Tan 1998). Fovell and Kim (2003) and Fovell et al. (2006) later described how gravity waves can become trapped by the upper-tropospheric line-leading anvil via a similar mechanism. These trapped preline gravity waves are of particular interest because they can then initiate convection farther downstream (Fovell and Kim 2003; Fovell et al. 2006); perhaps the preline updraft in Fig. 6c can be interpreted as an example of this process. It is difficult to conclusively demonstrate that the features in the 31 May MCS are gravity waves due to the temporal resolution of the data (length of the flight legs). But, because of their potential importance to the preline region, we are continuing to study other observations as

\footnotetext{
${ }^{4}$ An astute reviewer noted that the data of PJ00 did not reveal enhanced vertical shear in LS systems' environments. Subsequent work (PJ04a,b,c), however, revealed that PJ00 had unknowingly averaged front-fed and rear-fed LS systems, which masked the importance of the vertical wind shear in the front-fed LS cases.
} 
well as numerical simulations with the aim of understanding the purported waves.

Advances in these directions may improve our success in anticipating convective evolution, and perhaps hazardous weather, in similar high shear environments.

Acknowledgments. This research was supported by the National Science Foundation under Grant ATM0349069. The authors also acknowledge input and assistance from Drs. George Bryan and Rob Fovell. The BAMEX workshop participants also provided invaluable input. Much of this work was completed when the first two authors were at the University of NebraskaLincoln; the support and encouragement of the faculty and staff are gratefully acknowledged.

\section{REFERENCES}

Bryan, G. H., D. A. Ahijevych, C. A. Davis, M. L. Weisman, and R. Przyblylinski, 2004: An assessment of convective system structure, cold pool properties, and environment shear using observations from BAMEX. Preprints, 22d Conf. on Severe Local Storms, Hyannis, MA, Amer. Meteor. Soc., CD-ROM, 4.2.

Coniglio, M. C., D. J. Stensrud, and L. J. Wicker, 2006: Effects of upper-level shear on the structure and maintenance of strong quasi-linear mesoscale convective systems. J. Atmos. Sci., 63, $1231-1252$.

Davis, C., and Coauthors, 2004: The Bow Echo and MCV Experiment (BAMEX): Observations and opportunities. Bull. Amer. Meteor. Soc., 85, 1075-1093.

Doswell, C. A., III, and P. M. Markowski, 2004: Is buoyancy a relative quantity? Mon. Wea. Rev., 132, 853-863.

— - H. E. Brooks, and R. A. Maddox, 1996: Flash flood forecasting: An ingredients-based methodology. Wea. Forecasting, 11, 560-581.

Fovell, R. G., 2002: Upstream influence of numerically simulated squall-line storms. Quart. J. Roy. Meteor. Soc., 128, 893-912.

_, and P.-H. Tan, 1998: The temporal behavior of numerically simulated multicell-type storms. Part II: The convective cell life cycle and cell regeneration. Mon. Wea. Rev., 126, 551577.

— , and S.-H. Kim, 2003: Discrete propagation in numerically simulated nocturnal squall lines. Preprints, 10th Conf. on Mesoscale Processes, Portland, OR, Amer. Meteor. Soc., CDROM, 4.8.

— - G. L. Mullendore, and S.-H. Kim, 2006: Discrete propagation in numerically simulated nocturnal squall lines. Mon. Wea. Rev., 134, 3735-3752.

Fritsch, J. M., and G. S. Forbes, 2001: Mesoscale convective systems. Severe Convective Storms, Meteor. Monogr., No. 50, Amer. Meteor. Soc., 323-357.

Gal-Chen, T., 1978: A method for the initialization of the anelastic equations: Implications for matching models with observations. Mon. Wea. Rev., 106, 587-606.

Grady, R. L., and J. Verlinde, 1997: Triple-Doppler analysis of a discretely propagating, long-lived, high plains squall line. $J$. Atmos. Sci., 54, 2729-2748.

Hane, C. E., R. B. Wilhelmson, and T. Gal-Chen, 1981: Retrieval of thermodynamic variables within deep convective clouds:
Experiments in three dimensions. Mon. Wea. Rev., 109, 564576.

Houze, R. A., S. A. Rutledge, M. I. Biggerstaff, and B. F. Smull, 1989: Interpretation of Doppler weather radar displays of midlatitude mesoscale convective systems. Bull. Amer. Meteor. Soc., 70, 608-619.

James, R. P., J. M. Fritsch, and P. M. Markowski, 2005: Environmental distinctions between cellular and slabular convective lines. Mon. Wea. Rev., 133, 2669-2691.

Jorgensen, D. P., P. H. Hildebrand, and C. L. Frush, 1983: Feasibility test of an airborne pulse-Doppler meteorological radar. J. Climate Appl. Meteor., 22, 744-757.

—, T. Matejka, and J. D. DuGranrut, 1996: Multi-beam techniques for deriving wind fields from airborne Doppler radars. J. Meteor. Atmos. Phys., 59, 83-104.

—, M. A. LeMone, and S. B. Trier, 1997: Structure and evolution of the 22 February 1993 TOGA-COARE squall line: Aircraft observations of precipitation, circulation, and surface energy fluxes. J. Atmos. Sci., 54, 1961-1985.

Knight, C. A., L. J. Miller, and W. D. Hall, 2004: Deep convection and "first echoes" within anvil precipitation. Mon. Wea. Rev., 132, 1877-1890.

Knupp, K., 1987: Downdrafts with high plains cumulonimbi. Part I: General kinematic structure. J. Atmos. Sci., 44, 987-1008.

Leary, C. A., and R. A. Houze, 1979: Melting and evaporation of hydrometeors in precipitation from the anvil clouds of deep tropical convection. J. Atmos. Sci., 36, 669-679.

Mechem, D. B., R. A. Houze, and S. S. Chen, 2002: Layer inflow into precipitating convection over the western tropical $\mathrm{Pa}$ cific. Quart. J. Roy. Meteor. Soc., 128, 1997-2030.

Nachamkin, J. E., R. L. McAnelly, and W. R. Cotton, 2000: Interactions between a developing mesoscale convective system and its environment. Part I: Observational analysis. Mon. Wea. Rev., 128, 1205-1224.

O'Brien, J. J., 1970: Alternative solution to the classical vertical velocity problem. J. Appl. Meteor., 9, 197-203.

Parker, M. D., and R. H. Johnson, 2000: Organizational modes of midlatitude mesoscale convective systems. Mon. Wea. Rev., 128, 3413-3436.

_ precipitation. Part I: Governing dynamics. J. Atmos. Sci., 61, 1637-1655.

—, and _ 2004b: Simulated convective lines with leading precipitation. Part II: Evolution and maintenance. J. Atmos. Sci., 61, 1656-1673.

- , and,$- 2004 \mathrm{c}$ : Structures and dynamics of quasi-2D mesoscale convective systems. J. Atmos. Sci., 61, 545-567.

Rotunno, R., J. B. Klemp, and M. L. Weisman, 1988: A theory for strong, long-lived squall lines. J. Atmos. Sci., 45, 463-485.

Weisman, M. L., 1992: The role of convectively generated rearinflow jets in the evolution of long-lived mesoconvective systems. J. Atmos. Sci., 49, 1826-1847.

Wheatley, D. M., R. J. Trapp, and N. T. Atkins, 2006: Radar and damage analysis of bow echoes observed during BAMEX. Mon. Wea. Rev., 134, 791-806.

Yang, M.-J., and R. A. Houze Jr., 1995: Multicell squall-line structure as a manifestation of vertically trapped gravity waves. Mon. Wea. Rev., 123, 641-661.

Zhang, F., Z. Meng, D. Hawblitzel, C. A. Davis, and C. Snyder, 2004: Radar and damage analysis of bow echoes observed during BAMEX. Preprints, 22d Conf. on Severe Local Storms, Hyannis, MA, Amer. Meteor. Soc., CD-ROM, 5.5. 